\title{
Bronchoalveolar Lavage Fluid Utilized Ex Vivo to Validate In Vivo Findings: Inhibition of Gap Junction Activity in Lung Tumor Promotion is
} Toll-Like Receptor 4-Dependent

Thomas Hill III,\#, Ross S Osgood ${ }^{1, \#, ~ K a l p a n a ~ V e l m u r u g a n ~}{ }^{1, \#}$, Carla-Maria Alexander $^{1}$, Brad L Upham ${ }^{2}$ and Alison K Bauer ${ }^{1 *}$

${ }^{1}$ Department of Environmental and Occupational Health, Colorado School of Public Health, University of Colorado, Aurora, Colorado, USA

${ }^{2}$ Department of Pediatrics and Human Development, Michigan State University, Lansing, USA

"Authors Contributed Equally

\begin{abstract}
TLR4 protects against lung tumor promotion and pulmonary inflammation in mice. Connexin 43 (Cx43), a gap junction gene, was increased in TIr4 wildtype compared to TIr4-mutant mice in response to promotion, which suggests gap junctional intercellular communication (GJIC) may be compromised. We hypothesized that the early tumor microenvironment, represented by Bronchoalveolar Lavage Fluid (BALF) from Butylated hydroxytoluene (BHT; promoter)-treated mice, would produce TLR4-dependent changes in pulmonary epithelium, including dysregulation of GJIC in the TIr4-mutant (BALB ${ }^{\text {Lps- } d}$ ) compared to the TIr4-sufficient (BALB; wildtype) mice. BHT (4 weekly doses) was injected ip followed by BALF collection at $24 \mathrm{~h}$. BALF total protein and total macrophages were significantly elevated in BHT-treated BALB ${ }^{L p s-d}$ over BALB mice, similar to previous findings. BALF was then utilized in an ex vivo manner to treat C10 cells, a murine alveolar type II cell line, followed by the scrape-load dye transfer assay (GJIC), Cx43 immunostaining, and quantitative RT-PCR ( $M c p-1$, monocyte chemotactic protein 1). GJIC was markedly reduced in $\mathrm{C} 10$ cells treated with BHT-treated BALB ${ }^{L \rho s-d}$ BALF for 4 and $24 \mathrm{~h}$ compared to BALB and control BALF from the respective mice $(p<0.05)$. Mcp-1, a chemokine, was also significantly increased in the BHTtreated BALB ${ }^{L p s-d}$ BALF compared to the BALB mice, and $C \times 43$ protein expression in the cell membrane altered. These novel findings suggest signaling from the BALF milieu is involved in GJIC dysregulation associated with promotion and links gap junctions to pulmonary TLR4 protection in a novel ex vivo model that could assist in future potential tumor promoter screening.
\end{abstract}

Keywords: Bronchoalveolar Lavage Fluid (BALF); Butylated Hydroxytoluene (BHT); Connexin 43 (cx43); Gap junctions; Gap Junction Intercellular Communication (GJIC); Lung; Toll-like receptor 4 (TLR4); Tumor Promotion

\section{Introduction}

Lung cancer is a largely preventable disease in the U.S. and abroad [1]. Lung tumor formation is often a 2-stage process, starting with initiation, a direct mutagenic event, followed by promotion, a nongenotoxic event leading to the clonal expansion of initiated cells and tumor development. A common 2-stage model in the lung uses 3-Methylcholanthrene (3-MCA) followed by sequential dosing of Butylated Hydroxytoluene (BHT) in mice [2]. In more recent and past studies, the inflammatory characteristics of Bronchoalveolar Lavage Fluid (BALF) from treated mice have been used to describe changes in the local microenvironment that may be predictive of tumorigenesis [3-6].We previously demonstrated that functional Toll-Like Receptor 4 (TLR4), an innate immune receptor, is protective against inflammation and primary tumor formation in the mouse lung in vivo using the MCA/BHT 2-stage promotion model [3,7].

TLR4 both exacerbates and protects from inflammation and injury in pulmonary models. For example, TLR4 exacerbates lipopolysaccharide (LPS)-induced lung injury [8]. However, TLR4 protects against lung infection and other pulmonary diseases, such as emphysema $[9,10]$. In epidemiological studies, farm and textile workers had significant associations with decreased lung cancer risk in those individuals exposed to endotoxin (LPS) [11]. The primary receptor that binds endotoxin is TLR4 [8], therefore, it is likely involved in the protection observed with endotoxin exposure. Additionally, TLR4 confers protection in other organ systems, such as human gastric carcinomas [12].

Gap junctions are intercellular channels composed of connexin (cx) protein hexamers that permit cellular communication between neighboring cells and have been shown to regulate signal transduction pathways [13]. Impaired function of gap junctions secondary to toxicant exposure is strongly associated with pathological states, such as cancer and developmental defects $[13,14]$. Few studies have assessed pulmonary gap junction functionality, thus we have little understanding of the role(s) of gap junctions in pulmonary disease $[15,16]$. The scrape load dye-transfer (SL/DT) assay, a well-established in vitro assay [17] is commonly used to measure gap junction intracellular communication (GJIC). As such, GJIC has potential as a mechanistic biomarker to elucidate cellular signaling events involved in carcinogenesis that are not readily achievable in an in vivo system. Our previous transcriptomics study of TLR4-dependent effects in the mouse lung identified connexin 43 ( $\mathrm{Cx} 43)$, the major lung gap junction protein, as a gene potentially altered during early tumorigenesis [7]. While both the BHT promotion model and the SL/DT assay have been used independently to evaluate carcinogenic or toxic potential in vivo and in vitro, the coordinated use of these two tests as an ex vivo method to mechanistically examine the effects of tumor promoters is a novel adaptation with potential for both translational studies and clinical applications.

*Corresponding author: Alison K. Bauer, Department of Environmental and Occupational Health Mail Stop B119-V20, University of Colorado Denver Anschutz Medical Campus, 12850 East Montview Boulevard Rm. V20-125 Aurora, CO 80045 USA, Tel: 303-724-6297; Fax: 303-724-4495; E-mail: alison.bauer@ucdenver.edu

Received November 18, 2013; Accepted December 24, 2013; Published December 27, 2013

Citation: Hill T III, Osgood RS, Velmurugan K, Alexander CM, Upham BL, et al (2013) Bronchoalveolar Lavage Fluid Utilized Ex Vivo to Validate In Vivo Findings: Inhibition of Gap Junction Activity in Lung Tumor Promotion is Toll-Like Receptor 4-Dependent. J Mol Biomark Diagn 5: 160. doi:10.4172/2155-9929.1000160

Copyright: $\odot 2013$ Hill T III, et al. This is an open-access article distributed under the terms of the Creative Commons Attribution License, which permits unrestricted use, distribution, and reproduction in any medium, provided the original author and source are credited 
Citation: Hill T III, Osgood RS, Velmurugan K, Alexander CM, Upham BL, et al. (2013) Bronchoalveolar Lavage Fluid Utilized Ex Vivo to Validate In Vivo Findings: Inhibition of Gap Junction Activity in Lung Tumor Promotion is Toll-Like Receptor 4-Dependent. J Mol Biomark Diagn 5: 160. doi:10.4172/2155-9929.1000160

Most of the published literature to date has focused on the effects of complete carcinogens and mixtures of initiators and promoters on carcinogenesis (e.g. tobacco smoke), with little work directed at the promotion stage itself, which is the reversible stage of tumor development $[2,18]$. Examples of potential promoters include a long list of toxicants, such as polycyclic aromatic hydrocarbons that are known environmental contaminants attributable to combustion (fossil fuels, smoking) [16,19], and other pollutants such as Vanadium Pentoxide $\left(\mathrm{V}_{2} \mathrm{O}_{5}\right)$ [5]. The alteration of the inflammatory profile in the local microenvironment by such tumor promoting compounds (eg. BHT, PAHs, $\mathrm{V}_{2} \mathrm{O}_{5}$, or 12-O-tetradecanoylphorbol-13-acetate (TPA)) is a proposed mechanism for the actual events leading to tumor formation and progression $[4,16,20]$. If correct, sentinel events such as dysregulation of GJIC, should have some link to immune signaling within the cells, consistent with our in vivo findings for enhancement of inflammation and tumorigenesis in those mice with a mutation in Tlr4, as previously noted. In our studies, we hypothesized that the effects of the early tumor microenvironment, represented by BALF from BHT-treated mice, would produce TLR4-dependent changes in cultured pulmonary epithelium that will include differential inhibition of GJIC. To do so, we measured GJIC and various inflammatory markers in a murine pulmonary epithelial cell line (C10 cells) treated with BALF from BHTexposed mice or controls to discretely evaluate the existence of a TLR4dependent response to a known lung tumor promoter.

\section{Materials and Methods}

\section{Animal studies and Bronchoalveolar Lavage Fluid (BALF) processing}

The mice used were age matched 5-7 week old male BALB/c
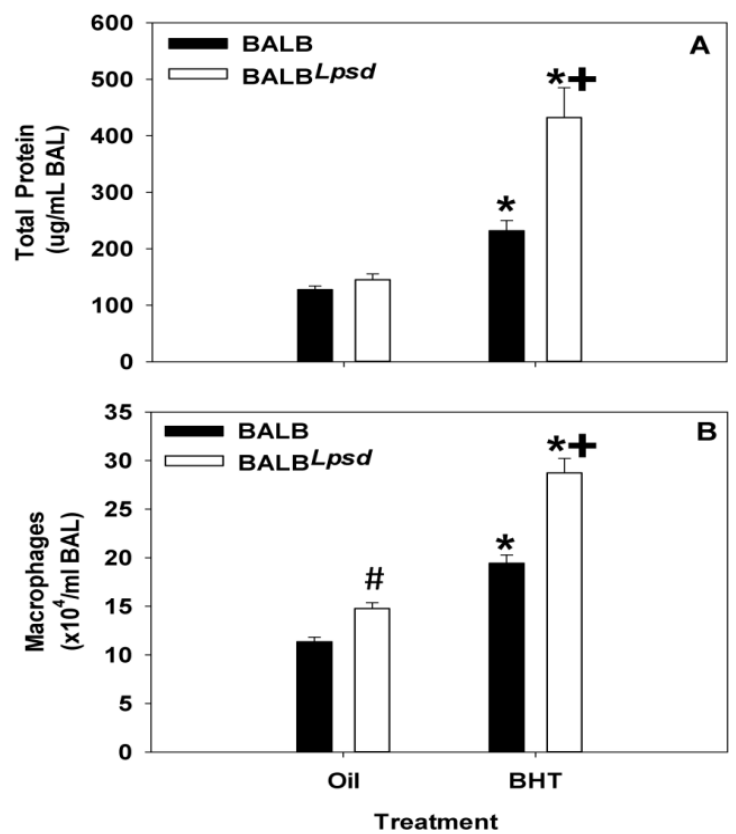

Figure 1: BHT produces an inflammatory profile in treated mice. (A) Tota protein content was increased in both strains in response to BHT, however was significantly higher in BHT treated BALB ${ }^{L p s-d}$ mice as indicated by the plus $\operatorname{sign}(\mathrm{N}=5 ; \mathrm{p}<0.001)$. (B) Total macrophage infiltration of BALF in BALB ${ }^{\text {Lps-d }}$ mice is statistically significant for all treatment groups $(N=5 ; p<0.05)$. Data presented as mean and SEM. * $\mathrm{P}<0.05$ for $\mathrm{BHT}$ compared to oil treatment groups; +, $p<0.05$ for BALB versus BALB ${ }^{\text {Lps-d }}$ mice; \#, $p<0.05$ for oil treatment between strains.
(BALB; Tlr4 sufficient) from Jackson Laboratories and C.C3H-Tlr4 $4^{\text {Lps-d }}$ (BALB ${ }^{L p s d}$, Tlr4 mutant) mice bred in the CU animal facility. The BALB $^{\text {Lpsd }}$ mice contain a mutant dominant negative Tlr4 that is not functional [21]. The animals were housed in the University of Colorado Animal Care Facility under environmentally controlled conditions and veterinary supervision. They were fed irradiated mouse chow (Harlan) and water ad libitum, and no pesticides or chemicals were used in the animal rooms for the duration of the experiments. All animal use was approved by the University of Colorado Denver Institutional Animal Care and Use Committee and follows the Helsinki convention for the use and care of animals.

BALB and $B A L B^{L p s-d}$ mice were administered intraperitoneal (ip) injections of BHT (Sigma, St. Louis, MO) dissolved in corn oil (vehicle control) once per week for $4 \mathrm{wks}(150$ (wk 1), $200 \mathrm{mg} / \mathrm{kg}$ (wks 2-4)), similar to previous studies $[3,4,22]$. Twenty-four hours after the final BHT dose, the mice were euthanized with Sleepaway $(120 \mathrm{mg} / \mathrm{kg}$; MWI, Boise, ID) and four bronchoalveolar Lavages performed using Hanks buffered salt solution (HBSS) at $35 \mathrm{ml} / \mathrm{kg}$ body weight. The initial lavage was reserved, centrifuged, and the cell-free supernatant frozen at $-80^{\circ} \mathrm{C}$ for use on the $\mathrm{C} 10$ cells after an aliquot was removed for total protein analysis (BioRad, Hercules, CA) following previous studies $[3,5,7,23,24]$. Total BAL protein is an indicator of lung hyperpermeability [25]. Cell pellets from all lavages were combined per mouse and total cells counted, followed by cytocentrifugation and Diffquick staining (Sigma, St. Louis, MO) for cell differentials using previously established methods $[3,5,7,23,24]$.

\section{In vitro studies}

A murine alveolar Type II cell line derived from BALB/c mice (C10 cells) was used, which was a kind gift from Dr. Lori Dwyer-Nield (University of Colorado) and originates from Smith et al. (1985) [26]. Many studies have used the C10 cells as a surrogate cell to mimic the type II cells in the lung in response to several toxicants and they have been well characterized $[16,27,28]$. The cells were maintained in confluent culture conditions with CMRL (Invitrogen, Grand Island, N.Y.) in $10 \%$ fetal bovine serum (FBS, Atlanta Biologicals; Atlanta, GA) medium supplemented with glutamine at $37^{\circ} \mathrm{C}$ and $5 \% \mathrm{CO}_{2}$.

For all ex vivo studies, C10 cells were grown to confluence over 2-3 days in 12 well dishes or on coverslips (immunocytochemistry). At confluence, the cells were switched to serum-free medium for $24 \mathrm{~h}$. The wells were then treated with BALF from individual mice diluted 1:4 in serum-free medium for 4 and $24 \mathrm{~h}$. Figure $1 \mathrm{~A}$ demonstrates differences in protein concentration between the strains. TPA, a liver tumor promoter and a known inhibitor of GJIC [29-32], was used as a treatment control along with serum-free medium.

\section{Scrape-load/dye-transfer (SL/DT) assay}

At 4 and $24 \mathrm{~h}, \mathrm{GJIC}$ was assessed using the $S L / D T$ assay, as previously reported $[16,17,29]$. The intact cell monolayer was rinsed 3 times with PBS, followed by application of Lucifer Yellow dye (1\% in PBS; Sigma) to the wells. Cuts were made in the monolayer with a surgical scalpel, and the cells were incubated for $3 \mathrm{~min}$ at room temperature. The wells were then rinsed 3 times with PBS and fixed with $4 \%$ formalin. A Nikon Eclipse Ti fluorescent microscope system (Nikon Instruments Inc.; Melville, NY) was used to capture images followed by Image J software (ImageJ; NIH) for quantitation of the digitized images. Calculations of GJIC were performed according to the published method [17]. 
Citation: Hill T III, Osgood RS, Velmurugan K, Alexander CM, Upham BL, et al. (2013) Bronchoalveolar Lavage Fluid Utilized Ex Vivo to Validate In Vivo Findings: Inhibition of Gap Junction Activity in Lung Tumor Promotion is Toll-Like Receptor 4-Dependent. J Mol Biomark Diagn 5: 160. doi:10.4172/2155-9929.1000160

Page 3 of 7

RNA isolation and real-time quantitative reverse transcriptase-polymerasechainreaction (qRT-PCR)

After exposure to BALF for $24 \mathrm{~h}$, RNA was extracted from C10 cells using the Nucleospin RNA II kit according to the manufacturer's protocol (Macherey-Nagel,Düren, Germany).Whole lung RNA was extracted using the RNAeasy miniprep kit (Qiagen, Germantown, Maryland). For qRT-PCR, $1 \mu \mathrm{g}$ of total RNA from each sample was converted to cDNA using oligo-dT, followed by PCR amplification in $50 \mu \mathrm{L}$ reaction volumes. The cDNA stock was used undiluted for qRT-PCR using gene specific, intron-spanning primers. Mcp-1primers:[1] 5'-GTCACCAAGCTCAAGAGAGA-3', (Rev) 5'-GTCACTCCTACAGAAGTGCT-3; Gja1 (Cx43) primers [1] 5'-CAACGTGGAGATGCACCTGAAG-3', (Rev) 5'-GCACTCAGGCTGA ACCCATAGA-3'. Primers for Cox-2 and $i N O S$ were previously published in Osgood et al. 2013 [16] and Buxade et al. 2012 [33]. All Mcp1, Cox-2, and iNOS reactions were carried out in a final volume of $25 \mu \mathrm{L}$ using KAPA SYBR ${ }^{\bullet}$ FAST master mix (Kapa Biosystems; Boston, MA) on a Master cycler EP Realplex ${ }^{4}$ qRT-PCR cycler (Eppendorf; Hauppauge, NY). Cx43 reactions were carried out similar to those in Bauer et al. 2011 [23] using Sybr Green (Applied Biosystems, Foster City, CA) and an ABI Prism 7700 Sequence Detection System (Applied Biosystems). Reactions were carried out in triplicate for each sample. Ct values for gene induction were normalized to those of $18 \mathrm{~S}$ as previously described [7], and calculations of fold induction determined [34]. All graphics are representative of the results from at least three independent experiments.

\section{Immunocytochemical staining}

After 4 and 24 h BALF exposures, the cells were fixed with $4 \%$ paraformaldehyde for 30 minutes. After washing in PBS, the cells were permeabilized, and blocked with $5 \%$ normal goat serum and $0.2 \%$ Triton X-100 in PBS for 90 min in a humidified chamber. Cells were then exposed to rabbit polyclonal $\mathrm{Cx} 43$ primary antibody (Cell Signaling, Danvers, MA) at a dilution of 1:150 in 3\% Bovine Serum Albumin (BSA) and incubated at $4^{\circ} \mathrm{C}$ overnight. The coverslips were again washed followed by incubation for $90 \mathrm{~min}$ at room temperature in the dark with the secondary antibody, Alexa Fluor 488-conjugated anti-rabbit IgG (1:250) (Invitrogen). After washing, coverslips were coated with Prolong Gold anti-fade mounting medium containing

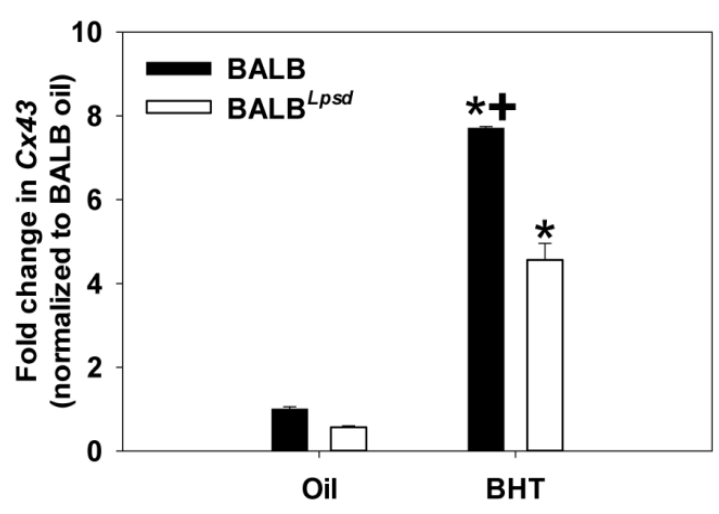

Figure 2: $C x 43$ mRNA expression in whole lung $24 \mathrm{~h}$ following in subchronic treatment of mice with BHT. Cx43 was first normalized to $18 \mathrm{~S}$ followed by normalization to the BALB oil control, as done previously [7]. Mean and SEM are presented of fold-change in $\mathrm{C} \times 43$ ( $\mathrm{n}=3$ mice per treatment; repeated three times). ${ }^{*}, \mathrm{P}<0.05$ for BHT compared to oil treatment groups;,$+ p<0.05$ for BALB versus BALB ${ }^{L p s-d}$ mice.
DAPI (Invitrogen), allowed to dry overnight, then sealed and imaged on a Nikon D-Eclipse $\mathrm{C} 1$ confocal microscope (Nikon Instruments Inc.; Melville, NY).

\section{Statistical Analysis}

The following statistical analyses were used to assess macrophage infiltration, total BALF protein, SL/DT assay and qRT-PCR: 2-way ANOVA with factors (strain X treatment) and a Student Newman Keuls post hoc comparison of relevant groups, using SigmaPlot (Systat Software; Chicago, IL).

\section{Results}

\section{Characterization of the inflammatory state of the BALF}

We demonstrated an increase in total BALF protein content and macrophage infiltration in all mice exposed to BHT (Figure 1A and 1B), similar to previous studies [3], for comparison to the analysis of gap junction activity in the experiments that followed (Figures 3 and 4). Total BALF protein significantly increased in both strains in response to BHT compared to oil controls ( $\mathrm{p} \geq 0.02$ ), however the BALB ${ }^{L p s-d}$ mice had significant elevations above that observed in the BALB BHTtreated mice (Figure 1A). Additionally, the magnitude of macrophage infiltration in the BALF of BALB ${ }^{L p s-d}$ mice was greater than that of the BALB, in response to BHT (Figure 1B). These data clearly show that an active inflammatory state was induced in all exposed animals, and that the collected BALF should therefore reflect the character of the local pulmonary microenvironment after exposure to a known promoter.

\section{GJIC is altered in C10 cells following treatment with BALF from BALB ${ }^{\mathrm{Lps}-\mathrm{d}}$ mice}

$C \times 43$ gene expression was reduced by BHT exposure in the lungs of BALB $^{\text {Lps-d }}$ mice compared to BALB mice (Figure 2) suggesting impaired gap junction signaling. In an effort to determine the actual effects on GJIC activity, we assessed the effects of BALF from treated and control mice on GIC in C10 cells. After treatment with BALF for $4 \mathrm{~h}$, gap junctions in the $\mathrm{C} 10$ cells were dysregulated in a manner consistent with both strain and treatment characteristics of the BALF donor (Figure 3). GJIC activity was reduced in response to BALF from $\mathrm{BALB}^{\text {Lps-d }}$ mice and approached the degree of inhibition produced by the treatment control, TPA. Following $24 \mathrm{~h}$ treatment with the BALF, we observed similar inhibition of GJIC in the BALB ${ }^{L p s-d}$ mice, although the magnitude of response was lower than that observed at $4 \mathrm{~h}$ (Figure 4). No statistically significant reduction in GJIC signaling was observed in the $\mathrm{C} 10$ cells following application of BALF from BALB mice regardless of treatment group or duration of exposure. These results indicate that Tlr4 protects cells from the disruption of GJIC by BHT induced release of inflammatory factors. The biphasic inhibition of GJIC by TPA peaks at $30 \mathrm{~min}$ and recovers at $24 \mathrm{~h}$, thus it was only used at $4 \mathrm{~h} \mathrm{[29]}$.

\section{GJIC inhibition correlates with redistribution of $\mathrm{Cx} 43$ protein but not $\mathrm{Cx} 43$ expression}

While GJIC was altered in response to BALF from BHT-treated mice, neither total protein levels or phosphorylation patterns of $\mathrm{Cx} 43$ were altered in the $\mathrm{C} 10$ cells at either 4 or $24 \mathrm{~h}$ (immunoblotting, data not shown). To determine if the observed inhibition of GJIC might be related to physical alteration of connexons, subcellular localization patterns of $\mathrm{Cx} 43$ within the cells was assessed using immunostaining (Figure 5). C10 cells treated with BALF from oil-treated mice did not affect the distribution patterns of $\mathrm{Cx} 43$ on the plasma membrane (Figure 5B, 5D) while cells treated with BALF collected from BALB 
Citation: Hill T III, Osgood RS, Velmurugan K, Alexander CM, Upham BL, et al. (2013) Bronchoalveolar Lavage Fluid Utilized Ex Vivo to Validate In Vivo Findings: Inhibition of Gap Junction Activity in Lung Tumor Promotion is Toll-Like Receptor 4-Dependent. J Mol Biomark Diagn 5: 160. doi:10.4172/2155-9929.1000160

Page 4 of 7
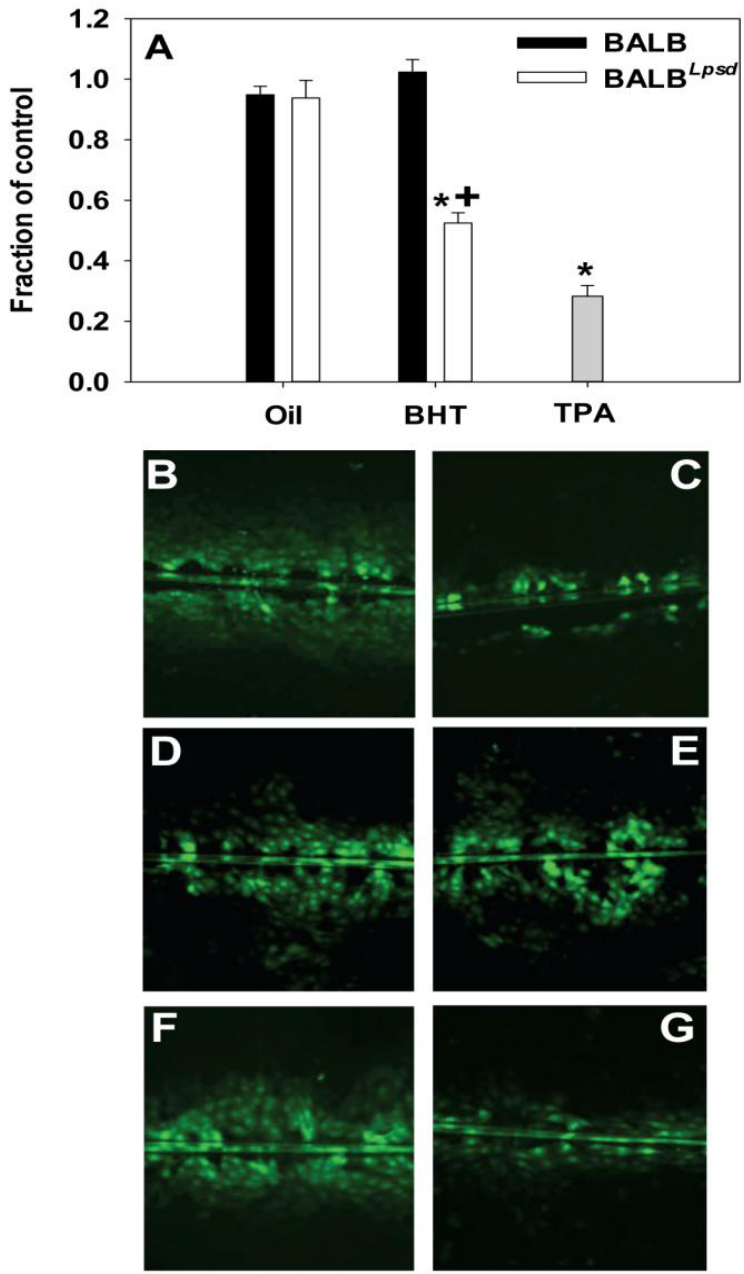

Figure 3: Inhibition of GJIC after a $4 \mathrm{~h}$ exposure to BALF is both treatment and strain dependent A) Graph of quantitated images from both BALB and BALB ${ }^{L p s-d}$ BALF-treated C10 cells following the SL/DT assay using Lucifer Yellow fluorescent dye. $\mathrm{N}=4-7$ per treatment group, repeated twice. Data were normalized to the medium control and presented as mean + SEM for fraction of control. * $\mathrm{P}<0.05$ for $\mathrm{BHT}$ compared to oil treatment groups;,$+ \mathrm{p}<0.05$ for BALB versus $B^{2}{ }^{L p s-d}$ mice. More inhibition is evident in cells treated with $B A L F$ from BHT-treated BALB ${ }^{L s s-d}(G)$ compared to all other BALF treatments. (B) $\mathrm{C} 10$ cells treated with serum-deprived media alone as control; (C) $\mathrm{C} 10$ cells treated with TPA as a known inhibitor of GJIC. (D) C10 cells treated with BALF from oil-treated BALB mice; (E) C10 cells treated with BALF from BHT-treated BALB mice; $(F)$ C10 cells treated with BALF from oil-treated BALB ${ }^{\text {Lps-d }}$ mice; $(G)$ C10 cells treated with BALF from BHT-treated BALB ${ }^{L p s-d}$ mice. Magnification is $100 \mathrm{X}$.

mice exposed to BHT displayed an increase in cytosolic localization of $\mathrm{Cx} 43$ but retained abundant $\mathrm{Cx} 43$ expression at the plasma membrane (Figure 5C). Cells treated with BALF collected from the BHT-treated BALB $^{\text {Lps-d }}$ mice displayed significant translocation of $\mathrm{Cx} 43$ from the plasma membrane to the cytosol at $4 \mathrm{~h}$ of exposure (Figure 5E). This effect was not seen in the $\mathrm{C} 10$ cells after a $24 \mathrm{~h}$ exposure period (data not shown) in spite of ongoing GJIC inhibition, suggesting that new connexin protein was synthesized, but failed to fully restore the connexon and regain normal function.

\section{Molecular marker of inflammation}

Monocyte Chemotactic Protein 1 (MCP-1 or CCL2), a chemokine that is a macrophage/monocyte chemoattractant, was previously identified in a transcriptomic study as a pathway involved in responsiveness to BHT in the BALB ${ }^{L p s-d}$ mice compared to BALB mice [7]. We observed significant increases in $M c p-1$ mRNA expression in C10 cells treated with BALF collected from the BALB ${ }^{L p s-d}$ mice exposed to BHT as compared to cells treated with BALF from the BHT-treated BALB mice and controls (Figure 6). We also evaluated Cox-2 and iNOS mRNA expression in the same manner as for $M c p-1$, but did not observe any significant changes among these inflammatory markers in response to the ex vivo BALF administration with either strain (data not shown).
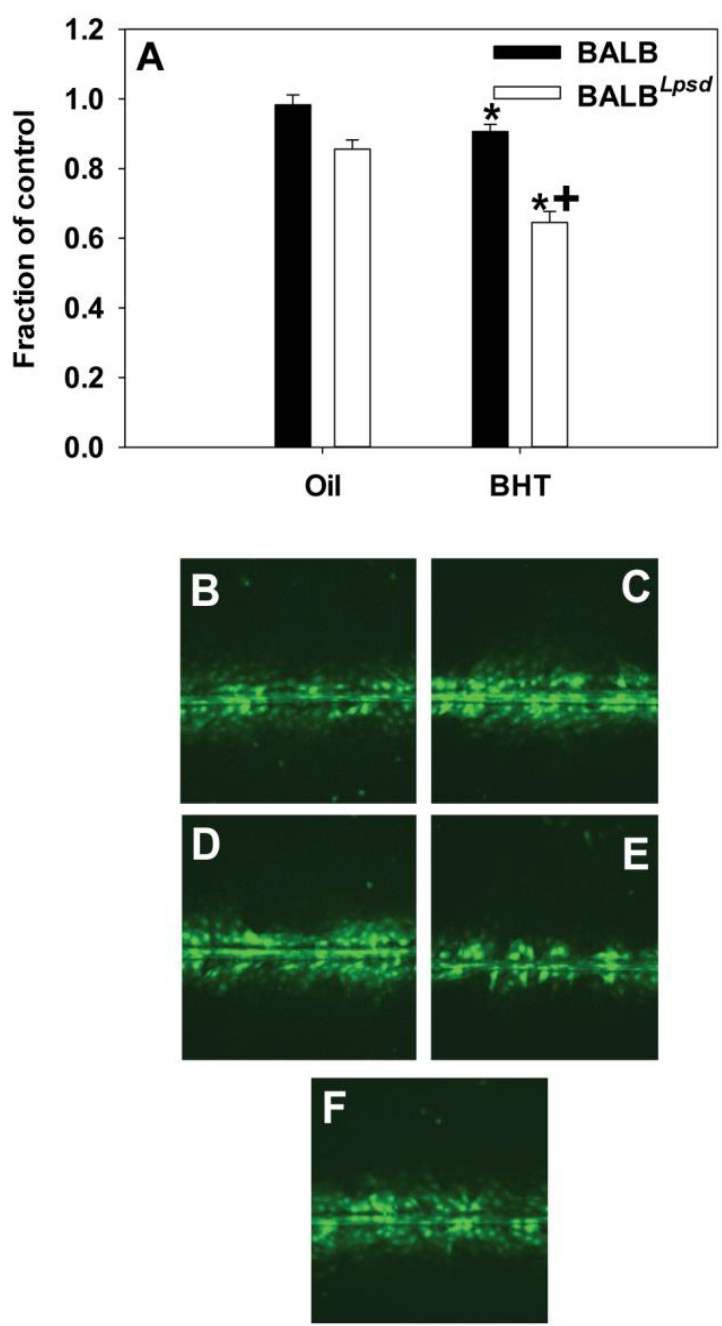

Figure 4: Inhibition of GJIC after a $24 \mathrm{~h}$ exposure to BALF is both treatment and strain dependent. (A) Quantitation of SL/DT assay demonstrating significant differences between strain BALF effects in the C10 cells following the SL/DT assay using Lucifer Yellow fluorescent dye. $\mathrm{N}=3-5$ per treatment group, repeated twice. Data were normalized to the medium control and presented as mean + SEM for fraction of control. *, $\mathrm{P}<0.05$ for BHT compared to oil treatment groups;,$+ p<0.05$ for BALB versus BALB ${ }^{\text {Lps- } d}$ mice. (B) Image of C10 cells treated with BALF from oil-treated BALB mouse; $(C)$ Image of of $C 10$ cells treated with BALF from BHT-treated BALB mouse; (D) Image of $C 10$ cells treated with BALF from oil-treated BALB ${ }^{L s-d}$ mouse; (E) Image of $\mathrm{C} 10$ cells treated with BALF from BHT-treated BALB ${ }^{\text {Lps-d } d}$ mouse; $(F)$ Image from C10 cells treated with serum-deprived media alone as control. Magnification is $100 \mathrm{X}$. 
Citation: Hill T III, Osgood RS, Velmurugan K, Alexander CM, Upham BL, et al. (2013) Bronchoalveolar Lavage Fluid Utilized Ex Vivo to Validate In Vivo Findings: Inhibition of Gap Junction Activity in Lung Tumor Promotion is Toll-Like Receptor 4-Dependent. J Mol Biomark Diagn 5: 160. doi:10.4172/2155-9929.1000160

Page 5 of 7
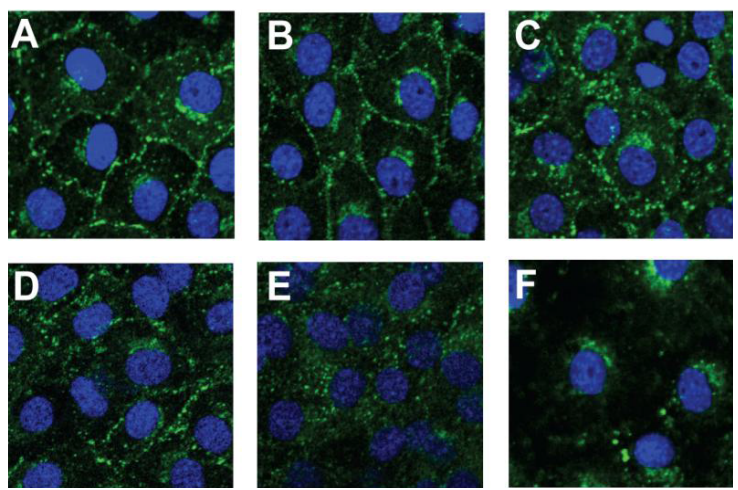

Figure 5: Connexin 43 membrane localization is altered in BALB ${ }^{\text {Lpsd }}$ mice Cx43 immunostaining in C10 cells exposed to BALF from BALB and BALB ${ }^{\text {Lpsd }}$ mice for $4 \mathrm{~h}$. DAPI was used as the nuclear stain and Alexa-Fluor 488 linked to specific $\mathrm{C} \times 43$ antibodies. (A) $\mathrm{C} 10$ cells treated with serum-deprived media as the control; (B) C10 cells treated with BALF from BALB oil-treated mice; $(C)$ C10 cells treated with BALF from BALB BHT-treated mice; (D) C10 cells treated with BALF from BALB ${ }^{L p s d}$ oil-treated mice; $(E)$ C10 cells treated with BALF from BALB ${ }^{\text {Lpsd }}$ BHT-treated mice; $(F)$ C10 cells treated with TPA as a tumor promoter control to demonstrate removal of $\mathrm{Cx} 43$, as observed previously $[16,29]$. $\mathrm{N}=2-3$ for each treatment group and repeated twice. Magnification, 1000X

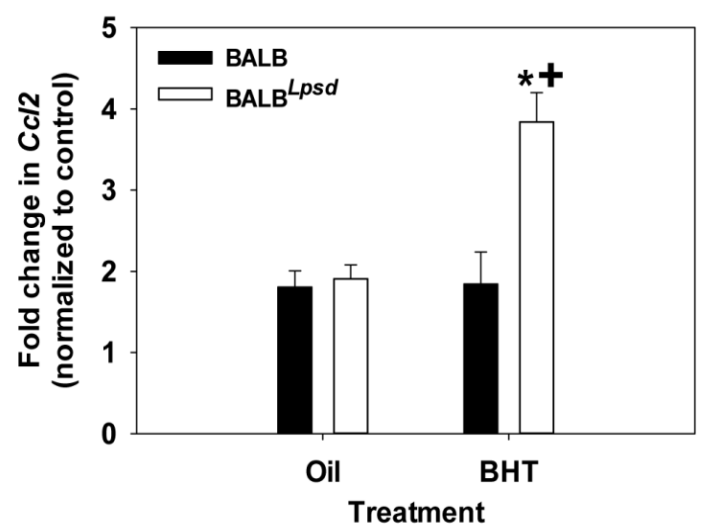

Figure 6: BALF treatment causes differential induction of an innate immune marker in vitro. A) $\mathrm{C} 10$ cells display higher levels of chemokine ligand $2(\mathrm{Cc} / 2$; $M c p-1)$ mRNA induction when exposed to BALF from BHT-treated BALB ${ }^{L p s-d}$ mice as opposed to BALB mice. Data were normalized to the medium control and are presented as mean fold induction and SEM; $\mathrm{N}=5$ for each treatment group.

\section{Discussion}

In our study, we evaluated TLR4 dependence of GJIC during alterations in the local microenvironment produced by the promoter BHT. To do so, we exposed both BALB (Tlr4 sufficient) and BALB ${ }^{\text {Lps-d }}$ (Tlr4 mutant) mice to BHT and collected their BALF. Strain or treatment differences in the cell-free BALF were documented and further characterized ex vivo using C10 cells treated with BALF. Our findings demonstrate that exposure of $\mathrm{C} 10$ cells to BALF from mice exposed to BHT produces unique ex vivo treatment and strain-based effects on cellular gap junctions that are TLR4-dependent. Interestingly, resveratrol, a phytoalexin present in grapes can reverse the GJICinhibitory effects of promoters [35], and these chemopreventative actions in cutaneous carcinomas appear to be TLR4-dependent [36].

Due to the limited metabolic capacity of the C10 cell line [37], it is likely that a xenobiotic or endogenous compound(s) already present in the BALF are responsible for the dysregulation of GJIC in C10 cells at 4 and $24 \mathrm{~h}$. The significant difference in the total protein content of the BALF from the exposed BALB ${ }^{L p s-d}$ mice, combined with the known rapid clearance of BHT from previously treated animals [38] suggests this may be protein-linked. The dependence of this dysregulation on a compromised TLR4 response and the magnitude of macrophage infiltration in $\mathrm{BALB}^{L p s-d}$ mice, suggests that the responsible mediator may be part of an immune signaling cascade. In addition, $M c p-1$ expression was induced in treated $\mathrm{C} 10$ cells, which are in parallel with the BALF macrophage response to BHT in vivo.

There is substantial supporting evidence that lung tumor promotion, particularly using the BHT model, involves inflammation $[4,5,7,25,39$ 43]. We refer the readers to several reviews on inflammation and lung cancer for more mechanistic details, as it is not the primary focus of these studies [20,22,44-46]. However, we and others have previously demonstrated using the BHT model that specific inflammatory cell types (ie. macrophages, lymphocytes, and neutrophils) are likely eliciting a cytokine/chemokine or other inflammatory mediator (ie. prostaglandins) response that can further lead to proliferation of initiated epithelial cells to advance the tumorigenic process $[3,4,25,40,43,47]$. Our current studies implicate inflammation as a major response to BHT, thus this BHT-induced tumor model will be expanded upon by further characterization of inflammatory cell types, such as lymphocyte phenotypes, determination of cytokine/chemokine profile responses, as well as identify involvement of downstream growth factor pathways. Some evidence, including our previous in vitro studies in C10 cells [16], supports a role for a cytokine associated inhibition of gap junctions. Whether this is a direct or indirect effect and the timing of this effect (acute vs chronic), needs to be further investigated using methods such as recombinant cytokine/chemokine administration or inhibition of cytokine/chemokine pathways using antibodies or siRNA techniques followed by evaluation of gap junctions. Thus far, one study in human airway epithelial cells using recombinant tumor necrosis factor a (TNF) demonstrated a direct inhibitory effect on gap junctions [48]. Future studies will investigate alterations in gap junction activity, using approaches such as those described above, that are both inflammationdependent and independent, as well as related mechanisms involved in altering gap junction activity and those inflammatory events that are unrelated to GJIC.

Connexin $43(\mathrm{Cx} 43)$ is a component of gap junctions that are expressed in the lung in multiple cell types, including both alveolar type II cells and bronchiolar Clara cells [13]. Type II cells and Clara cells are the progenitor cells for lung adenocarcinoma and are hence often studied as primary cellular targets for toxicants, such as tumor promoters [49-51]. Cx43 is the predominant pulmonary connexin, and is present and active in C10 cells [13,27]. Cx43 was significantly reduced in response to direct application of BHT (parent compound effect) in in vitro studies [27] and mice heterozygous for mutant $C \times 43$ are more susceptible to tumor development in a urethane tumorigenesis model [52]. Aberrant CX43 expression has also been reported in biopsies from in NSCLC patients [53]. Our immunoblots for Cx43 did not demonstrate differences in protein content between or within treatment groups. This suggests that the observed inhibition of GJIC might be due to a functional change in the connexins rather than simply protein ubiquitination and degradation, as has been reported with the direct use of toxicants on these cells in our laboratory [16]. Since the localization appears to change from membrane to cytosol in response to the BALF (Figure 5), we propose that this movement is a cell-directed reshuffling event which attempts to reorganize connexins back into functional gap junctions, as suggested by the incomplete return of gap junctional 
Citation: Hill T III, Osgood RS, Velmurugan K, Alexander CM, Upham BL, et al. (2013) Bronchoalveolar Lavage Fluid Utilized Ex Vivo to Validate In Vivo Findings: Inhibition of Gap Junction Activity in Lung Tumor Promotion is Toll-Like Receptor 4-Dependent. J Mol Biomark Diagn 5: 160. doi:10.4172/2155-9929.1000160

activity by $24 \mathrm{~h}$ compared to $4 \mathrm{~h}$. Cx 43 in functional gap junctions is known to display multiple phosphorylated forms in immunoblots. While we observed no changes in Cx43 phosphorylation patterns using several antibodies (Chemicon, Cell Signaling), it is possible that as yet undiscovered $\mathrm{Cx} 43$ phosphorylation sites could demonstrate phosphorylation differences after BALF exposure.

While the traditional method of direct toxicant exposure to cells in vitro has produced valid data in the past, the use of Bronchoalveolar Lavage Fluid (BALF) from exposed animals offers several advantages that make it a more thorough and useful approach to elucidate the cellular mechanisms in the many stages of carcinogenesis. First, it eliminates the issue of limited or unknown metabolic capacity in the pure in vitro system. By using biological fluids from an intact organism, the complete in vivo metabolite profile for the test compound is brought to bear upon the cultured cells, which greatly increases the potential for detection of toxicant effects. It also reduces the risk of false hits from the parent compound which may not be present at the target tissue site in vivo. Secondly, it has the possibility of expanding the translational capacity for mechanistic research into the stages of carcinogenesis in the human population. In this system, the use of biological fluids (eg. BALF) from human subjects could potentially be used as an evaluation tool (a biomarker) for exposure to cancer promoters. In addition, the system can determine cellular response patterns between in vitro models in human cell lines and lung cancer patients in both early and late stage pathologies. These potential comparisons would not only permit enhanced mechanistic explanation of the early, reversible stages of cancer development in humans, it may also present an enticing format for high-throughput evaluation of chemotherapeutic interventions as well.

Using this novel system we demonstrated marked inhibition of GJIC and alterations in Mcp-1 transcription patterns in C10 cells that are both treatment and strain dependent. These in vitro findings are in parallel with the inflammatory profile of the BALF collected from donor mice that were exposed in vivo. These novel findings suggest endocrine signaling from the inflammatory milieu are involved in the dysregulation of GIIC during the promotion phase of carcinogenesis. Furthermore, these data establish a link between dysregulation of gap junctions, tumor promotion, and the influence of TLR4 in an ex vivo model which will facilitate a mechanistic examination of these protective effects at the molecular level.

\section{Acknowledgement}

This work was supported by the American Cancer Society [RSG-10-16201-LIB] to [AKB] and the National Institute of Environmental Health Sciences [ES013268-01A2] to [BLU]. The American Cancer Society had no involvement in the design or in conducting this research.

\section{References}

1. Jemal A, Bray F, Center MM, Ferlay J, Ward E, et al. (2011) Global cancer statistics. CA Cancer J Clin 61: 69-90.

2. Malkinson AM, Koski KM, Evans WA, Festing MF (1997) Butylated hydroxytoluene exposure is necessary to induce lung tumors in BALB mice treated with 3-methylcholanthrene. Cancer Res 57: 2832-2834.

3. Bauer AK, Dixon D, DeGraff LM, Cho HY, Walker CR, et al. (2005) Toll-like receptor 4 in butylated hydroxytoluene-induced mouse pulmonary inflammation and tumorigenesis. J Natl Cancer Inst 97: 1778-1781.

4. Bauer AK, Dwyer-Nield LD, Hankin JA, Murphy RC, Malkinson AM (2001) The lung tumor promoter, Butylated Hydroxytoluene (BHT), causes chronic inflammation in promotion-sensitive BALB/cByJ mice but not in promotionresistant CXB4 mice. Toxicology 169: 1-15
5. Rondini EA, Walters DM, Bauer AK (2010) Vanadium pentoxide induces pulmonary inflammation and tumor promotion in a strain-dependent manner Part Fibre Toxicol 7: 9

6. Fritz JM, Dwyer-Nield LD, Malkinson AM (2011) Stimulation of neoplastic mouse lung cell proliferation by alveolar macrophage-derived, insulin-like growth factor-1 can be blocked by inhibiting MEK and PI3K activation. Mo Cancer 10: 76

7. Bauer AK, Fostel J, Degraff LM, Rondini EA, Walker C, et al. (2009) Transcriptomic analysis of pathways regulated by toll-like receptor 4 in a murine model of chronic pulmonary inflammation and carcinogenesis. Mol Cancer 8 : 107.

8. Poltorak A, He X, Smirnova I, Liu MY, Huffel CV, et al. (1998) Defective LPS signaling in $\mathrm{C} 3 \mathrm{H} / \mathrm{HeJ}$ and $\mathrm{C} 57 \mathrm{BL} / 10 \mathrm{ScCr}$ mice: mutations in TIr4 gene. Science 282: $2085-2088$

9. Faure K, Sawa T, Ajayi T, Fujimoto J, Moriyama K, et al. (2004) TLR4 signaling is essential for survival in acute lung injury induced by virulent Pseudomonas aeruginosa secreting type III secretory toxins. Respir Res 5: 1.

10. Zhang Y, Zhang X, Shan P, Hunt CR, Pandita TK, et al. (2013) A protective Hsp70-TLR4 pathway in lethal oxidant lung injury. J Immunol 191: 1393-1403.

11. Lundin Jl, Checkoway H (2009) Endotoxin and cancer. Environ Health Perspect 117: $1344-1350$

12. Hold GL, Rabkin CS, Chow WH, Smith MG, Gammon MD, et al. (2007) A functional polymorphism of toll-like receptor 4 gene increases risk of gastric carcinoma and its precursors. Gastroenterology 132: 905-912.

13. Johnson LN, Koval M (2009) Cross-talk between pulmonary injury, oxidant stress, and gap junctional communication. Antioxid Redox Signal 11: 355-367.

14. Trosko JE, Chang CC (1986) Oncogene and chemical inhibition of gapjunctional intercellular communication: implications for teratogenesis and carcinogenesis. Prog Clin Biol Res 209B: 21-31.

15. Islam MN, Das SR, Emin MT, Wei M, Sun L, et al. (2012) Mitochondrial transfer from bone-marrow-derived stromal cells to pulmonary alveoli protects against acute lung injury. Nat Med 18: 759-765.

16. Osgood RS, Upham BL, T Hill, Helms KL, Velmurugan K, et al. (2013) Polycyclic aromatic hydrocarbon-induced signaling events relevant to inflammation and tumorigenesis in lung cells are dependent on molecular structure. PLoS One 8: e65150

17. Upham BL (2011) Role of integrative signaling through gap junctions in toxicology. Curr Protoc Toxicol Chapter 2: Unit2.

18. Klaunig JE, Kamendulis LM, Xu Y (2000) Epigenetic mechanisms of chemical carcinogenesis. Hum Exp Toxicol 19: 543-555.

19. Upham BL, Weis LM, Trosko JE (1998) Modulated gap junctional intercellular communication as a biomarker of PAH epigenetic toxicity: structure-function relationship. Environ Health Perspect 106 Suppl 4: 975-981.

20. Malkinson AM (2005) Role of inflammation in mouse lung tumorigenesis: a review. Exp Lung Res 31: 57-82.

21. Vogel SN, Wax JS, Perera PY, Padlan C, Potter M, et al. (1994) Construction of a BALB/c congenic mouse, C.C3H-Lpsd, that expresses the Lpsd allele: analysis of chromosome 4 markers surrounding the Lps gene. Infect Immun 62: 4454-4459.

22. Bauer AK, Rondini EA (2009) Review paper: the role of inflammation in mouse pulmonary neoplasia. Vet Pathol 46: 369-390.

23. Bauer AK, Cho HY, Miller-Degraff L, Walker C, Helms K, et al. (2011) Targeted deletion of Nrf2 reduces urethane-induced lung tumor development in mice. PLoS One 6: e26590.

24. Bauer AK, Rondini EA, Hummel KA, Degraff LM, Walker C, et al. (2011) Identification of candidate genes downstream of TLR4 signaling after ozone exposure in mice: a role for heat-shock protein 70 . Environ Health Perspect 119: 1091-1097.

25. Bauer AK, Dwyer-Nield LD, Keil K, Koski K, Malkinson AM (2001) Butylated hydroxytoluene (BHT) induction of pulmonary inflammation: a role in tumor promotion. Exp Lung Res 27: 197-216.

26. Smith GJ, Lykke AW (1985) Characterization of a neoplastic epithelial cel strain derived by dexamethasone treatment of cultured normal mouse type 2 pneumocytes. J Pathol, 147: 165-172. 
Citation: Hill T III, Osgood RS, Velmurugan K, Alexander CM, Upham BL, et al. (2013) Bronchoalveolar Lavage Fluid Utilized Ex Vivo to Validate In Vivo Findings: Inhibition of Gap Junction Activity in Lung Tumor Promotion is Toll-Like Receptor 4-Dependent. J Mol Biomark Diagn 5: 160. doi:10.4172/2155-9929.1000160

27. Guan X, Hardenbrook J, Fernstrom MJ, Chaudhuri R, Malkinson AM, et al. (1995) Down-regulation by butylated hydroxytoluene of the number and function of gap junctions in epithelial cell lines derived from mouse lung and rat liver. Carcinogenesis 16: 2575-2582

28. Rice PL, Barrett BS, Fritz JM, Srebernak MC, Kisley LR, et al. (2010) Regulation of cytokine-induced prostanoid and nitric oxide synthesis by extracellular signal-regulated kinase $1 / 2$ in lung epithelial cells. Exp Lung Res 36: 558-571.

29. Upham BL, Blaha L, Babica P, Park JS, Sovadinova I, et al. (2008) Tumor promoting properties of a cigarette smoke prevalent polycyclic aromatic hydrocarbon as indicated by the inhibition of gap junctional intercellular communication via phosphatidylcholine-specific phospholipase C. Cancer Sci 99: 696-705

30. Upham BL, Weis LM, Rummel AM, Masten SJ, Trosko JE (1996) The effects of anthracene and methylated anthracenes on gap junctional intercellular communication in rat liver epithelial cells. Fundam Appl Toxicol 34: 260-264.

31. Vang O, Wallin $\mathrm{H}$, Autrup $\mathrm{H}$ (1995) Inhibition of intercellular communication by condensates of high and low tar cigarettes. Arch Toxicol 69: 415-420.

32. Leithe E, Rivedal E (2004) Ubiquitination and down-regulation of gap junction protein connexin-43 in response to 12-O-tetradecanoylphorbol 13-acetate treatment. J Biol Chem 279: 50089-50096.

33. Buxadé M, Lunazzi G, Minguillón J, Iborra S, Berga-Bolaños R, et al. (2012) Gene expression induced by Toll-like receptors in macrophages requires the transcription factor NFAT5. J Exp Med 209: 379-393.

34. Bookout AL, Cummins CL, Mangelsdorf DJ, Pesola JM, Kramer MF (2001) High-Throughput Real-Time Quantitative Reverse Transcription PCR, in Current Protocols in Molecular Biology. John Wiley \& Sons, Inc.

35. Upham BL, Guzvic M, Scott J, Carbone JM, Blaha L, et al. (2007) Inhibition of gap junctional intercellular communication and activation of mitogen-activated protein kinase by tumor-promoting organic peroxides and protection by resveratrol. Nutr Cancer 57: 38-47.

36. Yusuf N, Nasti TH, Meleth S, Elmets CA (2009) Resveratrol enhances cellmediated immune response to DMBA through TLR4 and prevents DMBA induced cutaneous carcinogenesis. Mol Carcinog 48: 713-723.

37. Reiners JJ Jr, Pavone A, Cantu AR, Auerbach C, Malkinson AM (1992) Differential expression of cytochrome P-450 in proliferating and quiescent cultures of murine lung epithelial cells. Biochem Biophys Res Commun 183 193-198.

38. Witschi H, Malkinson AM, Thompson JA (1989) Metabolism and pulmonary toxicity of butylated hydroxytoluene (BHT). Pharmacol Ther 42: 89-113.

39. Keith RL, Miller YE, Hoshikawa Y, Moore MD, Gesell TL, et al. (2002) Manipulation of pulmonary prostacyclin synthase expression prevents murine lung cancer. Cancer Res 62: 734-740.

40. Meyer AM, Dwyer-Nield LD, Hurteau G, Keith RL, Ouyang Y, et al. (2006) Attenuation of the pulmonary inflammatory response following butylated hydroxytoluene treatment of cytosolic phospholipase $\mathrm{A}(2)$ null mice. American Journal of Physiology-Lung Cellular and Molecular Physiology 290 L1260-L1266.
41. Redente EF, Dwyer-Nield LD, Barrett BS, Riches DW, Malkinson AM (2009) Lung tumor growth is stimulated in IFN-gamma-/- mice and inhibited in IL4Ralpha-/- mice. Anticancer Res 29: 5095-5101.

42. Moghaddam SJ, Li H, Cho SN, Dishop MK, Wistuba II, et al. (2009) Promotion of lung carcinogenesis by chronic obstructive pulmonary disease-like airway inflammation in a K-ras-induced mouse model. Am J Respir Cell Mol Biol 40 443-453.

43. Vikis HG, Gelman AE, Franklin A, Stein L, Rymaszewski A, et al. (2012) Neutrophils are required for 3-methylcholanthrene-initiated, butylated hydroxytoluene-promoted lung carcinogenesis. Mol Carcinog 51: 993-1002.

44. Bauer AK, Hill T 3rd, Alexander CM (2013) The involvement of NRF2 in lung cancer. Oxid Med Cell Longev 2013: 746432.

45. Bauer AK, Malkinson AM, Kleeberger SR (2004) Susceptibility to neoplastic and non-neoplastic pulmonary diseases in mice: genetic similarities. Am J Physiol Lung Cell Mol Physiol 287: L685-703.

46. Schottenfeld D, Beebe-Dimmer J (2006) Chronic inflammation: a common and important factor in the pathogenesis of neoplasia. CA Cancer J Clin 56: 69-83.

47. Redente EF, Higgins DM, Dwyer-Nield LD, Orme IM, Gonzalez-Juarrero M, e al. (2010) Differential polarization of alveolar macrophages and bone marrowderived monocytes following chemically and pathogen-induced chronic lung inflammation. J Leukoc Biol 88: 159-168.

48. Chanson M, Berclaz PY, Scerri I, Dudez T, Wernke-Dollries K, et al. (2001) Regulation of gap junctional communication by a pro-inflammatory cytokine in cystic fibrosis transmembrane conductance regulator-expressing but not cystic fibrosis airway cells. Am J Pathol 158: 1775-1784.

49. Dwyer-Nield LD, Thompson JA, Peljak G, Squier MK, Barker TD, et al. (1998) Selective induction of apoptosis in mouse and human lung epithelial cell lines by the tert-butyl hydroxylated metabolite of butylated hydroxytoluene: a proposed role in tumor promotion. Toxicology 130: 115-127.

50. Schottenfeld D (2005) Etiology and Epidemiology of Lung Cancer, in Lung Cancer- Principles and Practice. Lippincott Williams and Wilkins: Philadelphia.

51. Chaudhuri R, Sigler K, Dupont E, Trosko JE, Malkinson AM, et al. (1993) Gap junctional intercellular communication in mouse lung epithelial cell lines: effects of cell transformation and tumor promoters. Cancer Lett 71: 11-18.

52. Avanzo JL, Mesnil M, Hernandez-Blazquez FJ, Mackowiak II, Mori CM, et al. (2004) Increased susceptibility to urethane-induced lung tumors in mice with decreased expression of connexin43. Carcinogenesis 25: 1973-1982.

53. Chen JT, Cheng YW, Chou MC, Sen-Lin T, Lai WW, et al. (2003) The correlation between aberrant connexin 43 mRNA expression induced by promoter methylation and nodal micrometastasis in non-small cell lung cancer. Clin Cancer Res 9: 4200-4204 